\title{
Article \\ Lysozyme Influence on Monolayers of Individual and Mixed Lipids
}

\author{
Juan Torrent-Burgués (i)
}

check for updates

Citation: Torrent-Burgués, J. Lysozyme Influence on Monolayers of Individual and Mixed Lipids. Colloids Interfaces 2022, 6, 15. https://doi.org/10.3390/ colloids6010015

Academic Editors: Wuge Briscoe and Pierre Bauduin

Received: 25 November 2021

Accepted: 11 February 2022

Published: 21 February 2022

Publisher's Note: MDPI stays neutral with regard to jurisdictional claims in published maps and institutional affiliations.

Copyright: (C) 2022 by the author. Licensee MDPI, Basel, Switzerland. This article is an open access article distributed under the terms and conditions of the Creative Commons Attribution (CC BY) license (https:// creativecommons.org/licenses/by/ $4.0 /)$.
Department of Chemical Engineering, Universitat Politècnica de Catalunya, C/Colom 1, E08222 Terrassa, Spain; juan.torrent@upc.edu; Tel.: +34-937398043

\begin{abstract}
Fatty acids, cholesterol, and phospholipids are amphiphilic compounds of biological interest, which form ordered monolayers mimicking biomembranes, and can be studied with the Langmuir technique using surface pressure-area isotherms and compressibility plots. Proteins are also components of biomembranes or are present in body fluids. In this study, the influence of lysozyme on different films of a fatty acid (stearic acid or oleic acid), cholesterol, a phospholipid (dipalmitoylphosphatidylcholine, DPPC, or palmitoyloleoylphosphatidylcholine, POPC), and mixtures of them is presented using a $0.9 \%$ saline solution as subphase. Results show that the presence of lysozyme alters the lipid monolayer formation in an important way at the beginning (low surface pressures) and the middle (intermediate surface pressures) parts of the isotherm. At high surface pressures, the phospholipids DPPC and POPC and the saturated fatty acid, stearic acid, expel lysozyme from the surface, while oleic acid and cholesterol permit the presence of lysozyme on it. The mixtures of oleic acid-DPPC also expel lysozyme from the surface at high surface pressures, while mixtures of oleic acid-POPC and cholesterol-POPC permit the presence of lysozyme on it. The compressibility of the monolayer is affected in all cases, with an important reduction in the elastic modulus values and an increase in the fluidity, especially at low and intermediate surface pressures.
\end{abstract}

Keywords: fatty acid; cholesterol; phospholipid; mixed lipids; Langmuir monolayer; lysozyme; compressibility

\section{Introduction}

Fatty acids, cholesterol, and phospholipids are of biological interest, and they can form ordered and compact monolayers. References to previous studies can be found in [1-3]. Some articles on single fatty acids and single phospholipids published in the last years are reported in reference [4]. Recent articles related to mixtures of fatty acid and a phospholipid are those of [5-15], and articles related to mixtures of cholesterol and a phospholipid are those of [16-22].

Interactions of proteins with lipid films and membranes are of great interest for biological systems such as tear films and cellular membranes. Works studying the surface properties of protein solutions and the influence of proteins on lipid monolayers are those of references [23-38] and those reported in reference [39]. Sah et al. [26] observed that reversible hysteresis persists if the protein molecules contain effective positive or negative surface charges. For neutral conditions, irreversibility in the hysteresis behavior dominates. They also found that at lower surface pressures, a monomolecular layer of bovine serum albumin, BSA, is formed on the water surface and molecules start to lift up when increasing the surface pressure. Depending on the surface pressure and surface charge of BSA, a monomolecular or bimolecular layer of BSA is formed on the water surface; however, a bimolecular layer is observed when the $\mathrm{pH}$ is closer to the BSA isoelectric point of $\approx 5$. Pasquier et al. [38] studied protein interfacial layers of ovalbumin and lysozyme at a free air-water interface, using neutron reflectivity and null-ellipsometry. These authors found that the combined effect of a positive charge of protein and the presence of advection flow 
(convection towards the interface) induce the formation of interfacial multilayers. In the absence of advection flow, ovalbumin and lysozyme form monolayers. Lipid monolayers are considered as a model for half a membrane, being valuable to characterize proteinmembrane interactions. Nobre et al. [40] presented a critical review on the subject of interactions of bioactive molecules and nanomaterials with Langmuir monolayers.

Only some of these cited works have studied lysozyme [25,27] or the influence of lysozyme on lipid films [28,32,33,35,36]. Miñones et al. [25] studied how to obtain a wellspread monolayer of lysozyme at the air-water interfaces. Tihonov et al. [27] studied dynamic surface properties of lysozyme solutions. Chernysheva et al. [28] studied the influence of non-ionic surfactants on lysozyme adsorption at aqueous-air and aqueousorganic liquid interfaces. Ohno et al. [33] studied the interfacial tension in the adsorption of lysozyme onto lipid monolayer formed at a water-chloroform interface. Derde et al. [35,36] studied lysozyme and dry-heated lysozyme interactions with membrane lipid monolayers using a lipopolysaccharide from E. coli, and they observed that lysozyme has a high affinity for the lipopolysaccharide monolayer due to polysaccharide moieties. Nishimura et al. [32] investigated the effect of lysozyme adsorption on the interfacial rheology of DPPC and cholesteryl myristate films, and they found that the adsorption of lysozyme into a cholesteryl myristate or a DPPC-cholesteryl myristate film resulted in a more expanded film and increased the compressibility.

The results reported in the bibliography indicate that, in general, the systems fatty acid-phospholipid present miscibility, but the interactions may be more attractive with $\Delta A<0$ (see Equation (2)), or more repulsive with $\Delta A>0$, depending on the fatty acid and phospholipid. A saturated fatty acid affords more rigidity to the phospholipid monolayer, but an unsaturated fatty acid affords more fluidity to the phospholipid monolayer. A saturated fatty acid interacts more favorably with a saturated phospholipid than with an unsaturated phospholipid. Some authors point out that between a saturated fatty acid and an unsaturated phospholipid, phase separation occurs at certain values of surface pressure and composition. In the particular case of cholesterol, as a rule, cholesterol induces a contraction of the phospholipid monolayer with $\Delta A<0$, indicating attractive interactions, but this fact also depends on the phospholipid having a stronger interaction with PC than with PE phospholipids.

Fatty acids, cholesterol, phospholipids, and their mixtures are present in the lipid layer of the tear film, and lysozyme is a protein present in the aqueous layer of the tear film that interacts with the lipids of the lipid layer [41]. Stearic acid and oleic acid are typical fatty acids abundant in natural systems, thus are models for the study. DPPC and POPC are typical phospholipids and models for the study. In previous work, the influence of lysozyme on individual lipid films using water subphase was studied [38]. In the present work, the influence of lysozyme on mixed lipid films with oleic acid-DPPC, oleic acid-POPC, cholesterol-POPC, and on the individual lipids using $\mathrm{NaCl} 0.9 \%$ water subphase, a more physiological medium, has been studied. Thus, the aim of the work is first to study these particular lipid systems, which present an unsaturation on the fatty acid and/or in the phospholipid, and to see their behavior, and secondly, the influence of lysozyme on them. For that, surface pressure-area isotherms were registered, and from these, the elasticity modulus, $C_{S}{ }^{-1}$ (Equation (1)), was calculated, where $\pi$ is the surface pressure and $A$ the area.

$$
C_{S}^{-1}=-A\left(\frac{d \pi}{d A}\right)_{T}
$$

For the mixed films, the increment of area $\Delta A$ (Equation (2)), or excess area $A^{E}$, can be calculated at several surface pressures, where $A_{12}$ is the mean area per molecule for the mixture, $X_{1}$ and $X_{2}$ the molar fractions of the components, and $A_{1}$ and $A_{2}$ the area per molecule of each individual component at a fixed surface pressure.

$$
\Delta A=A^{E}=A_{12}-\left(X_{1} \cdot A_{1}+X_{2} \cdot A_{2}\right)
$$




\section{Materials and Methods}

\subsection{Materials}

Oleic acid (OA), purity $\geq 99 \%$, was provided by Fluka (Madrid, Spain). Palmitoyloleoylphosphatidylcholine (POPC), purity $\geq 99 \%$, was purchased from Avanti Polar Lipids (Alabaster, AL, USA). Stearic acid (SA), purity $\geq 98.5 \%$, dipalmitoylphosphatidylcholine (DPPC), purity $\geq 99 \%$, cholesterol (CHO), purity $\geq 99 \%$, and lysozyme from chicken egg white, purity $\geq 98 \%$, were provided by Sigma-Aldrich (Sant Louis, MO, USA). NaCl, purity $\geq 99.0 \%$, and chloroform, purity $\geq 99.5 \%$, of analytical grade from Sigma-Aldrich, were used in solution preparation. Water was ultrapure MilliQ ${ }^{\circledR}$ (resistivity $18.2 \mathrm{M} \Omega \cdot \mathrm{cm}$ and $\mathrm{pH}=6.8)$.

\subsection{Techniques}

Langmuir monolayer formation was carried out on a trough (Nima Technology, Cambridge, UK) model 1232D1D2 equipped with two movable barriers. The surface area of this trough was $1200 \mathrm{~cm}^{2}$, dimensions $60 \mathrm{~cm} \times 20 \mathrm{~cm}$. The surface pressure was measured using paper Whatman 1 held by a Wilhelmy balance connected to a microelectronic system registering the surface pressure $(\pi)$. In one case, the subphase used in these experiments was a saline solution at $0.9 \%$ in $\mathrm{NaCl}$. In the other case, the subphase used was a saline solution at $0.9 \% \mathrm{NaCl}$ containing lysozyme at a concentration of $0.1 \mathrm{~g} \cdot \mathrm{L}^{-1}(\mathrm{pH}=5.0)$. This concentration of lysozyme is close to that in the tear film. Before the subphase addition, the trough was cleaned twice with chloroform and once with MilliQ ${ }^{\circledR}$ quality water. Residual impurities were cleaned from the air-liquid interface by surface suctioning. Solutions of the lipids were prepared using chloroform, at concentrations of $1 \mathrm{mg} \cdot \mathrm{mL}^{-1}$, and spread at the air-liquid interface using a high-precision Hamilton microsyringe. For the binary mixtures of lipids, corresponding volumes of each lipid solution in chloroform were mixed to attain a total lipid concentration of $1 \mathrm{mg} \cdot \mathrm{mL}^{-1}$, and from that, the molar fraction was calculated. These molar fractions are indicated in the captions of Figure 7, Figure 8 and Figure 9. The barrier closing rate was fixed at $50 \mathrm{~cm}^{2} \cdot \mathrm{min}^{-1}\left(2.5 \mathrm{~cm} \cdot \mathrm{min}^{-1}\right)$. Surface pressure-area isotherm was recorded, in one case, for the lysozyme subphase without lipid addition, and in the other case, the recording was carried out adding the lipid solution drop by drop to the subphase, waiting $15 \mathrm{~min}$ for perfect spreading and solvent evaporation, and then compressing by closing barriers. The X-axis of the isotherm plot represents the area per molecule referred to the corresponding lipid, except for the isotherm of lysozyme alone where the surface area is used, and in the case of mixed lipids, it is the mean area per molecule, where the lipid composition is considered. Experiments were conducted at $22 \pm 1{ }^{\circ} \mathrm{C}$ in a closed chamber and repeated at least 3 times for reproducibility control. The reproducibility was good.

\section{Results}

\subsection{Surface Lysozyme Behaviour}

In this section, the surface behavior of lysozyme is reported. First, the surface tension of the subphase with lysozyme was measured, obtaining a value of $70.4 \mathrm{mN} \cdot \mathrm{m}^{-1}$ for the $0.1 \mathrm{~g} \cdot \mathrm{L}^{-1}\left(6.94 \times 10^{-6} \mathrm{M}\right)$ lysozyme solution. This value is only slightly lower than that of water $\left(72.6 \mathrm{mN} \cdot \mathrm{m}^{-1}\right.$ at $\left.22{ }^{\circ} \mathrm{C}\right)$. The surface tension was also measured during the time interval of $1 \mathrm{~h}$, as well as before and after registering the isotherm with open barriers in the trough, and no differences were observed. This result agrees with those of Tihonov et al. [27] and Crawford et al. [42]. These authors observed the influence of time in the measured value of surface tension, but it seems that the initial value of surface tension of lysozyme does not change during approximately the first $90 \mathrm{~min}$ [27], and a similar fact has been observed for $\beta$-galactosidase [42].

Figure 1 shows the isotherm using a subphase with lysozyme at a concentration of $0.1 \mathrm{~g} \cdot \mathrm{L}^{-1}$, without a lipid layer. A total of $15 \mathrm{~min}$ elapsed between pouring the subphase and the start of the isotherm. At first, it is seen that lysozyme shows an isotherm, reaching a surface pressure value around $25 \mathrm{mN} \cdot \mathrm{m}^{-1}$. It was also observed that a certain hysteresis 
is present when performing a cycle, but the compression-decompression process is quite reversible, and a second cycle (not shown) presents only small differences in respect to the first one. The hysteresis is less important when lower surface pressures are reached. In a spectroscopic study by Crawford et al. [42], performing compression-decompression cycles, no influence of these on the $\beta$-galactosidase structure was reported, which agrees with our results. Thus, we can assume no significant changes in lysozyme structure during the time-scale of our experiments by the effect of compression and that the possible aggregation or conformational changes induced during compression are reversible and revert during decompression. Sah et al. [26], studying hysteresis on BSA layers, found reversible hysteresis if the protein molecules contain effective positive or negative surface charges. As lysozyme, with an isoelectronic point at $\mathrm{pH}=11.4$, presents a positive charge at $\mathrm{pH}=5$, our results agree with those of Sah et al. [26].

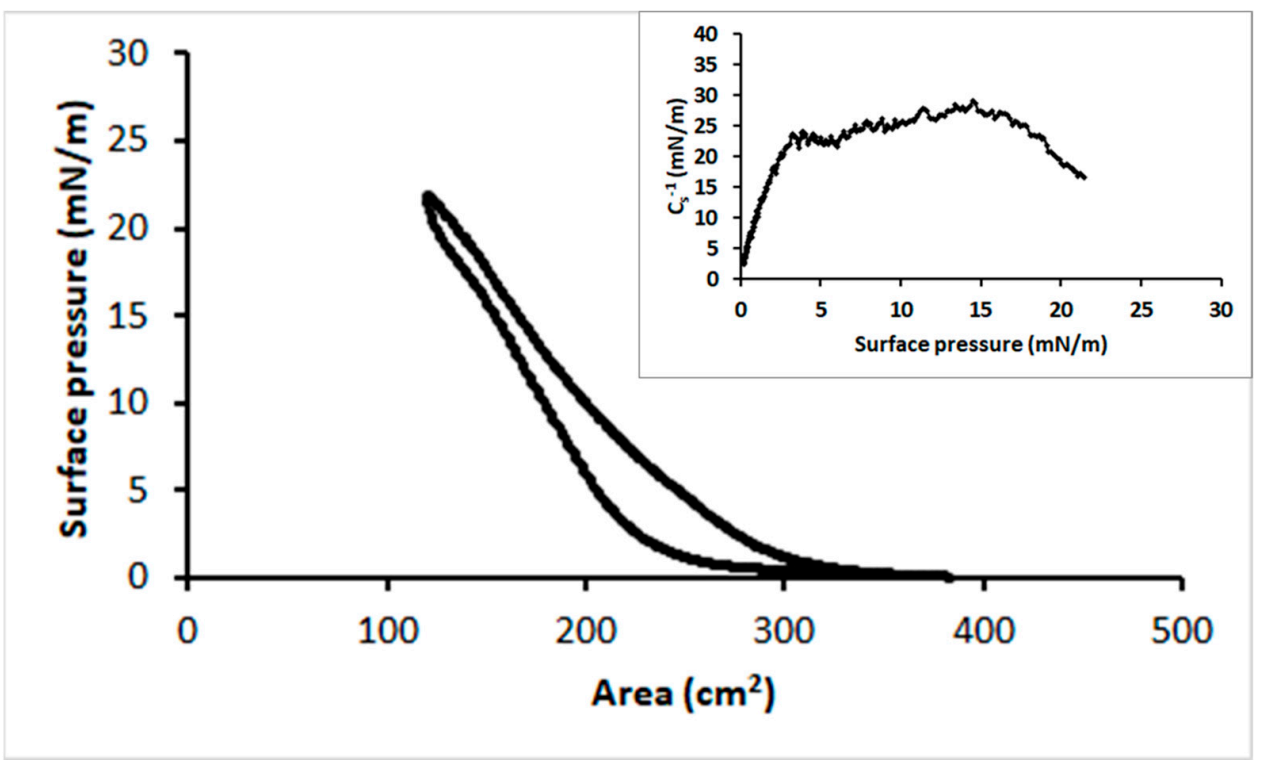

Figure 1. Surface pressure-area isotherm, with cycle, for lysozyme at a concentration of $0.1 \mathrm{~g} \cdot \mathrm{L}^{-1}$. Inset: Elastic modulus curve from the isotherm (only compression) of Figure 1.

An analysis of the compressibility can be done (Inset Figure 1). The values of elastic modulus, $C_{S}{ }^{-1}$ (Equation (1)), indicate a liquid expanded, LE, state with a maximum value of $C_{S}{ }^{-1}$ around $30 \mathrm{mN} \cdot \mathrm{m}^{-1}$ (LE: $12.5<C_{S}{ }^{-1}<100 \mathrm{mN} \cdot \mathrm{m}^{-1}$, LC: $100<C_{S}{ }^{-1}<250$, S: $C_{S}{ }^{-1}>250$ [43-45] and Supplementary Information). This plot presents two maxima and a minimum in between, which corresponds to a change in the molecular organization.

Caselli et al. [46] point out that changes in orientation of adsorbed proteins are in fact probable because the polypeptide must re-adapt to the less hydrophilic air phase, but unfolding may be only partial with the proteins preserving their functions.

\subsection{Influence of Lysozyme over Lipid Monolayers}

The presence of lysozyme in the subphase and its influence on lipid monolayers has been investigated. The used lipids are DPPC, POPC, oleic acid (OA), stearic acid (SA), and cholesterol (CHO). In all cases, 15 min elapsed after pouring the subphase and prior to the lipid spreading, and then $15 \mathrm{~min}$ more for perfect lipid spreading and solvent evaporation. At first, a notable influence is observed due to the presence of lysozyme since the isotherms start at high surface pressure values. When spreading the lipid, a high value of surface pressure is obtained against the value of zero observed when the same amount of lipid was spread in the absence of lysozyme. The isotherms in the presence of lysozyme present more inflection points, as are visible in the isotherm plots and more clearly in the compressibility plots. Below, the obtained isotherms for the different pure lipids are shown. In all cases the subphase composition is $0.1 \mathrm{~g} \cdot \mathrm{L}^{-1}$ lysozyme $+0.9 \% \mathrm{NaCl}$. 


\subsubsection{Stearic Acid}

Figure 2 shows the surface pressure-area isotherms for SA in the absence and in the presence of lysozyme. There is a clear influence of lysozyme on the SA isotherm. The isotherm starts at a surface pressure value of around $16 \mathrm{mN} \cdot \mathrm{m}^{-1}$, and then there is a slow increase of surface pressure when compressing until an area value of around $35 \AA^{2} \cdot$ molecule $^{-1}$. Then, the surface pressure increases fast up to a value of $47 \mathrm{mN} \cdot \mathrm{m}^{-1}$, where an inflection occurs, and a short plateau is reached. This plateau is followed by a new sharp increase until reaching the collapse at a surface pressure of $62 \mathrm{mN} \cdot \mathrm{m}^{-1}$, which is slightly higher than for SA in the absence of lysozyme (collapse at $57 \mathrm{mN} \cdot \mathrm{m}^{-1}$ ). The collapse areas are similar.

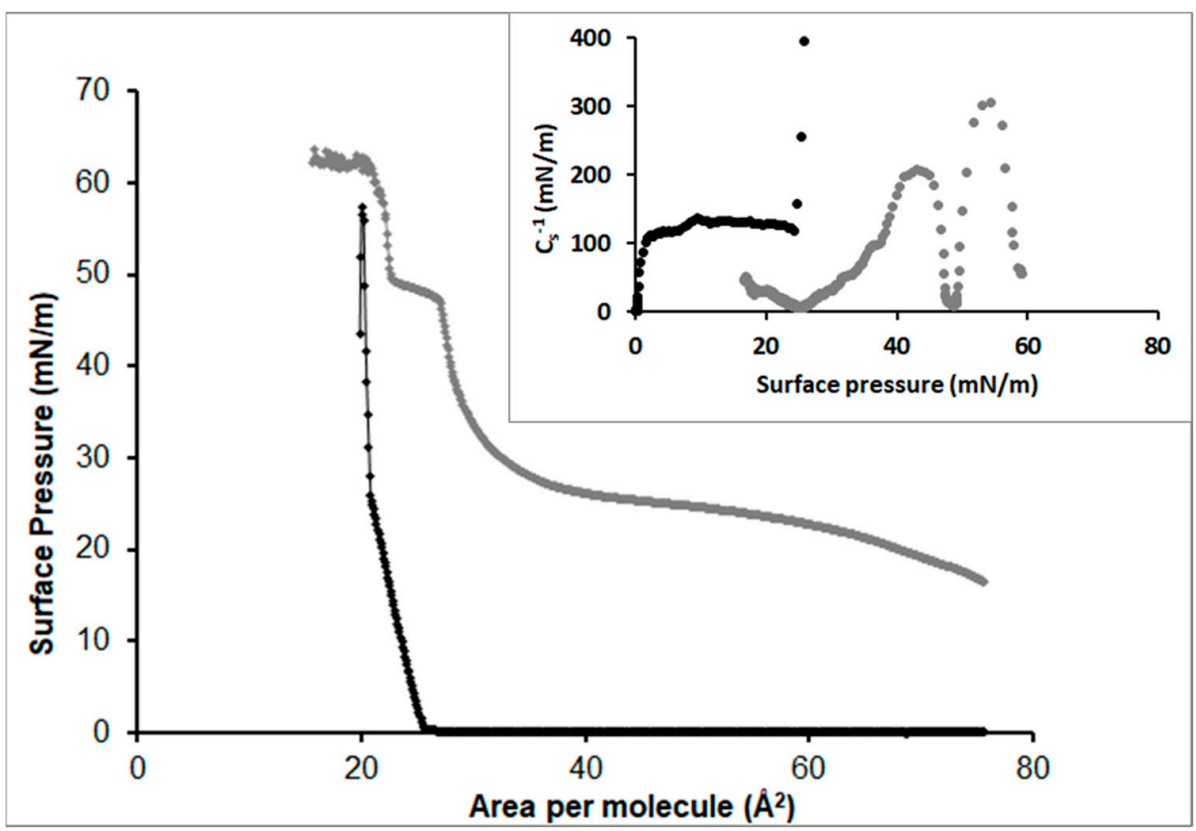

Figure 2. Surface pressure-area isotherms for SA in the absence (black) and in the presence of lysozyme (grey). Inset: Elastic modulus curves from the isotherms of Figure 2 for SA in the absence (black) and in the presence of lysozyme (grey).

Analyzing the compressibility plots (Inset Figure 2), the $C_{S}{ }^{-1}$ values for SA in the absence of lysozyme show a liquid condensed, LC, state that changes to solid, $\mathrm{S}$, at a surface pressure around $25 \mathrm{mN} \cdot \mathrm{m}^{-1}$. This corresponds to the inflection point in the isotherm. In the presence of lysozyme, the $C_{S}{ }^{-1}$ values correspond to a LE state at the beginning, with a change to LC when compressing (around $36 \mathrm{mN} \cdot \mathrm{m}^{-1}$ ) and to $S$ at higher compressions (around $49 \mathrm{mN} \cdot \mathrm{m}^{-1}$ ).

The isotherms at low compressions indicate the presence of lysozyme in the surface competing with SA. As the isotherm in the presence of lysozyme become closer to that in its absence as compression increases, it seems to indicate that lysozyme is displaced by SA, allowing the compaction of a monolayer of SA in the surface, but still perturbed by the presence of lysozyme.

\subsubsection{Oleic Acid}

Figure 3 shows the surface pressure-area isotherms for OA in the absence and in the presence of lysozyme. The isotherm of OA also shows a shift to higher areas and surface pressures due to the presence of lysozyme. In this case, the influence of lysozyme over the surface pressure and area at the collapse is more noticeable, occurring both at a higher area and higher surface pressure. In the absence of lysozyme, the collapse occurs at $28 \mathrm{mN} \cdot \mathrm{m}^{-1}$, but in the presence of lysozyme, the collapse occurs at $37 \mathrm{mN} \cdot \mathrm{m}^{-1}$. 


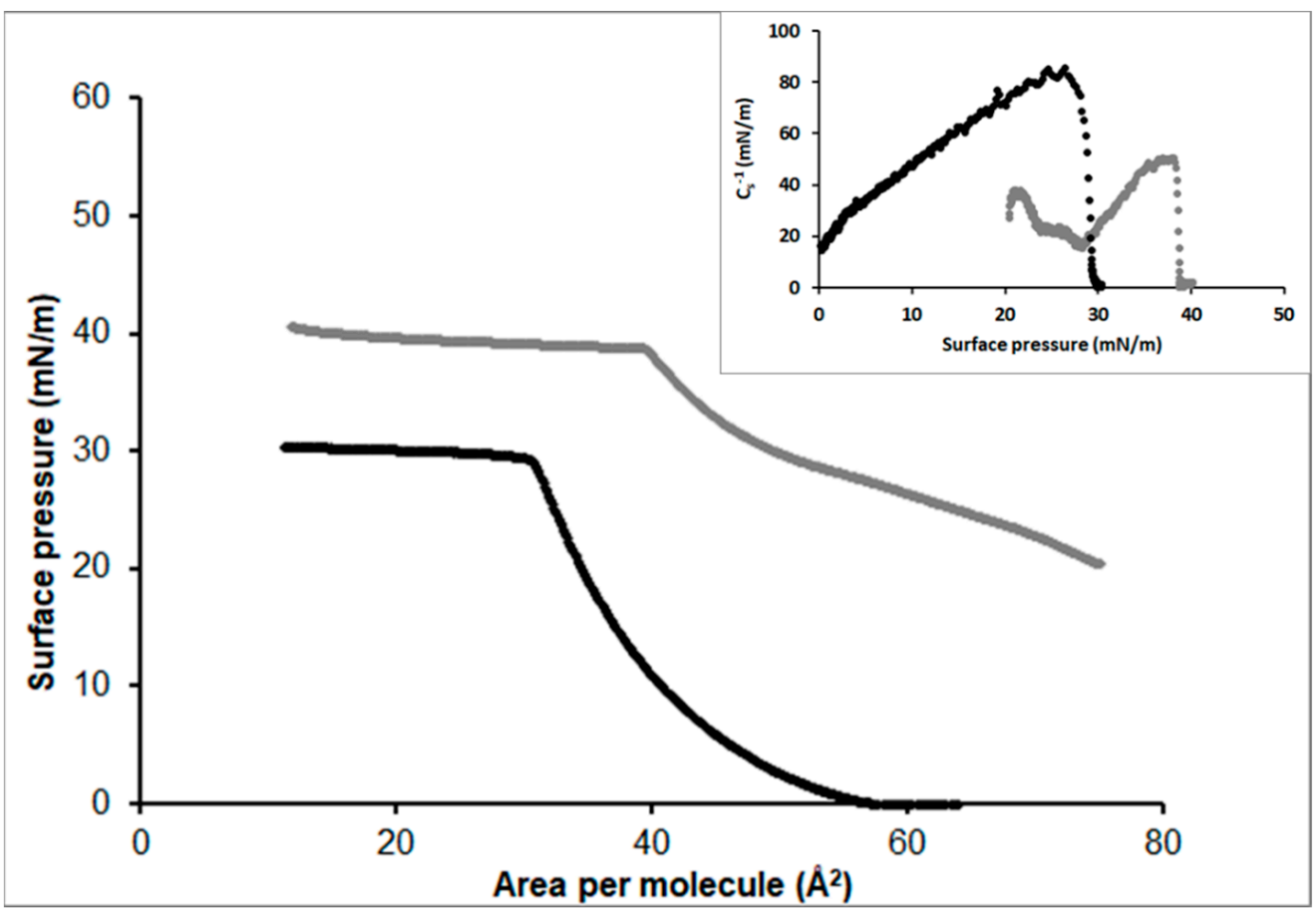

Figure 3. Surface pressure-area isotherms for OA in the absence (black) and in the presence (grey) of lysozyme. Inset: Elastic modulus curves from the isotherms of Figure 3 for OA in the absence (black) and in the presence (grey) of lysozyme.

The $C_{S}{ }^{-1}$ values for OA (Inset Figure 3) show a LE state, and in the presence of lysozyme, a LE state but with lower values of $C_{S}{ }^{-1}$ is also observed. In the presence of lysozyme, an inflection is observed at $22-23 \mathrm{mN} \cdot \mathrm{m}^{-1}$, and another small inflection at $27-28 \mathrm{mN} \cdot \mathrm{m}^{-1}$, the latest being similar to the value of surface pressure for the collapse of OA in the absence of lysozyme. After that, the isotherm in the presence of lysozyme follows a behavior more similar to that of OA without lysozyme.

The characteristics of the isotherms also indicate that OA tends to displace lysozyme at higher compressions, but as the OA does not compact as strong as SA or DPPC does (see next section), the lysozyme molecules compete with the OA molecules on the surface.

\subsubsection{DPPC}

Figure 4 shows the surface pressure-area isotherms for DPPC in the absence and in the presence of lysozyme. Apart from the displacement of the isotherm in the presence of lysozyme, in this case, it is also observed that lysozyme influence on the phase change of DPPC, even the phase change from LE to LC occurs at a similar area per molecule. The collapse surface pressure values are 52 and $57 \mathrm{mN} \cdot \mathrm{m}^{-1}$ in the absence and in the presence of lysozyme, respectively.

The $C_{S}{ }^{-1}$ values for DPPC (Inset Figure 4) in the absence of lysozyme show a change from LE to LC state, at a surface pressure around $7.5 \mathrm{mN} \cdot \mathrm{m}^{-1}$. In the presence of lysozyme, the $C_{S}{ }^{-1}$ values remain low, in a LE state, until higher compressions where values corresponding to a LC state are reached. After some weak inflections at 17 and $32 \mathrm{mN} \cdot \mathrm{m}^{-1}$, at a surface pressure around $42 \mathrm{mN} \cdot \mathrm{m}^{-1}$ appears the inflection point leading to $\mathrm{LC}$, and after that, at higher surface pressures, the isotherm and $C_{S}{ }^{-1}$ plot shapes are close to those of DPPC.

It means that at higher compressions, the DPPC molecules tend to arrange in a more compact way and to displace the lysozyme molecules from the surface. The influence of lysozyme is more marked at the LE state than at the LC state. 


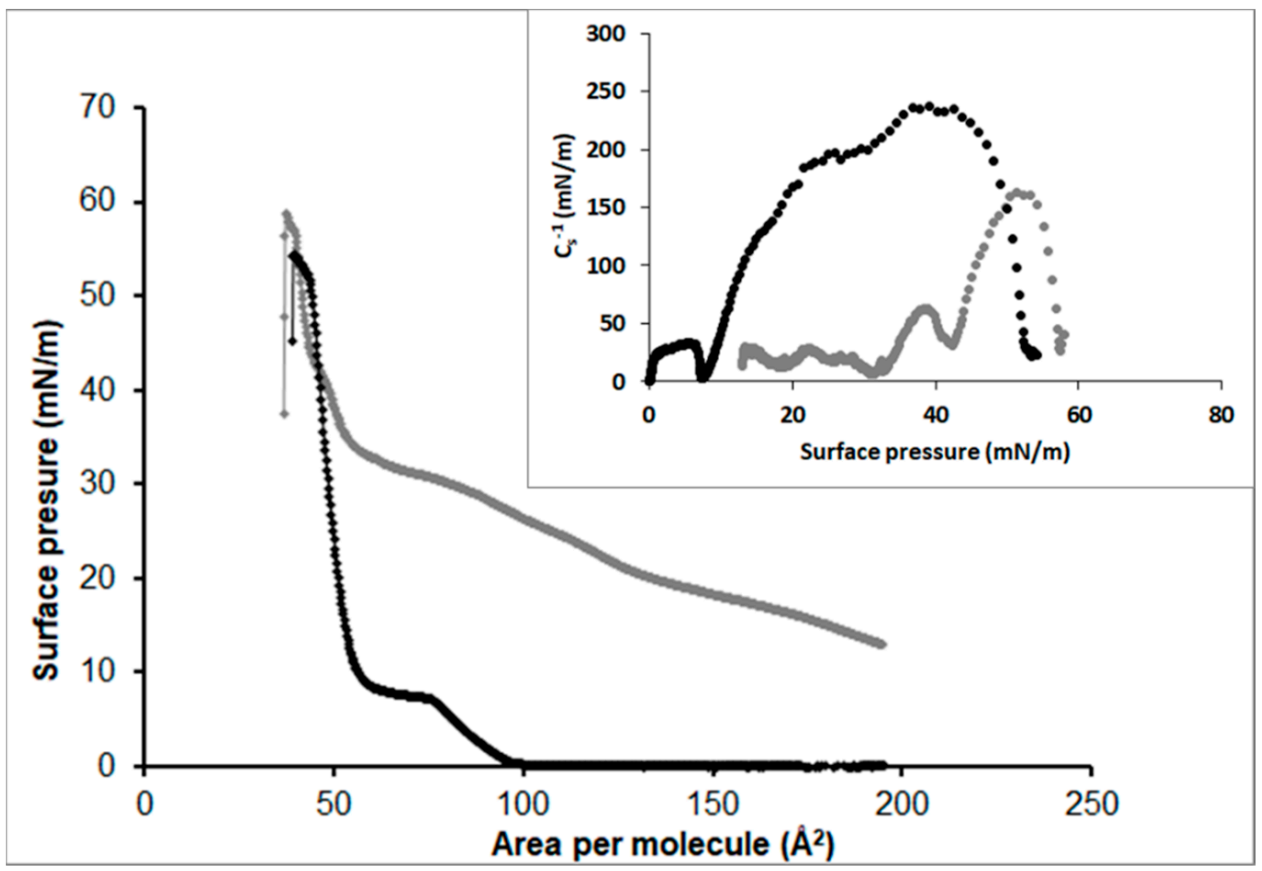

Figure 4. Surface pressure-area isotherms for DPPC in the absence (black) and in the presence (grey) of lysozyme. Inset: Elastic modulus curves from the isotherms of Figure 4 for DPPC in the absence (black) and in the presence (grey) of lysozyme.

\subsubsection{POPC}

Figure 5 shows the surface pressure-area isotherms for POPC in the absence and in the presence of lysozyme. For POPC, it is observed that lysozyme induces several inflections in the POPC isotherm. At higher compressions, the slope of the isotherms tends to that of the POPC alone. The surface pressure and area at the collapse are similar, the collapse occurring at $47 \mathrm{mN} \cdot \mathrm{m}^{-1}$.

The $C_{S}{ }^{-1}$ values for POPC (Inset Figure 5) show a LE state, even close to a LC state at high compressions. In the presence of lysozyme, the $C_{S}{ }^{-1}$ values indicate a LE state, but with lower values than in its absence, but at a surface pressure around $33 \mathrm{mN} \cdot \mathrm{m}^{-1}$ the film compacts arriving at $C_{S}{ }^{-1}$ values close to those of POPC without lysozyme. The different inflection points, in the presence of lysozyme, are observed at 18, 23 (very weak inflection), 33 , and $42 \mathrm{mN} \cdot \mathrm{m}^{-1}$. At high surface pressure values, POPC tends to displace lysozyme from the surface.

\subsubsection{Cholesterol}

Figure 6 shows the surface pressure-area isotherms for $\mathrm{CHO}$ in the absence and in the presence of lysozyme. From the isotherms, it is observed that the influence on $\mathrm{CHO}$ is notable, and the surface pressure and area at the collapse are different from those of $\mathrm{CHO}$ in the absence of lysozyme. In the absence of lysozyme, collapse occurs at $43 \mathrm{mN} \cdot \mathrm{m}^{-1}$, and in its presence occurs at $53 \mathrm{mN} \cdot \mathrm{m}^{-1}$. The $\mathrm{CHO}$ isotherm shifts to higher areas in the presence of lysozyme. In addition, several inflections appear in the presence of lysozyme, more clearly observable from the $C_{S}{ }^{-1}$ plots (inset Figure 6). These inflections are observed at surface pressures around 22,25 , and $45 \mathrm{mN} \cdot \mathrm{m}^{-1}$. The latter nearly corresponds with the collapse in the absence of lysozyme.

The $C_{S}{ }^{-1}$ values for $\mathrm{CHO}$ (Inset Figure 6) show an $\mathrm{S}$ state. In the presence of lysozyme, the $C_{S}{ }^{-1}$ values indicate a LE state that changes to LC at high compressions, or even to $S$ state at surface pressures higher than $35 \mathrm{mN} \cdot \mathrm{m}^{-1}$, but with $C_{S}{ }^{-1}$ values remaining lower than those of individual $\mathrm{CHO}$. 


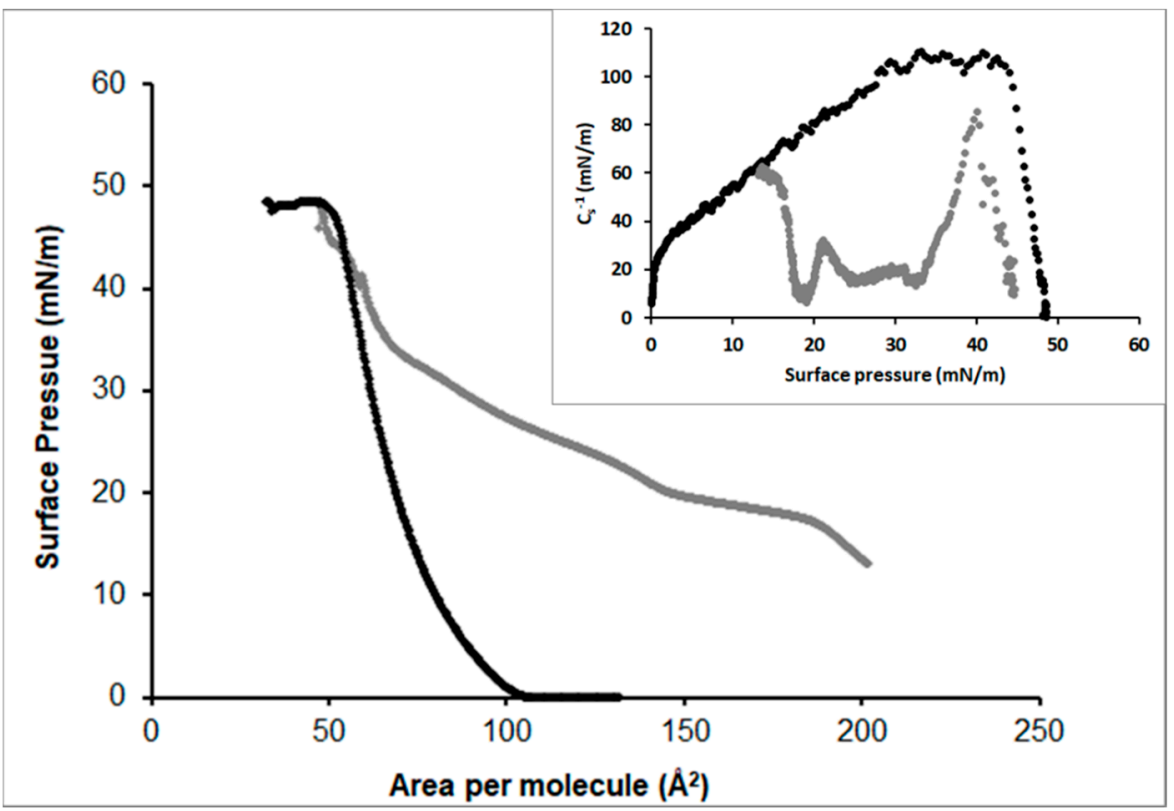

Figure 5. Surface pressure-area isotherms for POPC in the absence (black) and in the presence (grey) of lysozyme. Inset: Elastic modulus curves from the isotherms of Figure 5 for POPC in the absence (black) and in the presence (grey) of lysozyme.

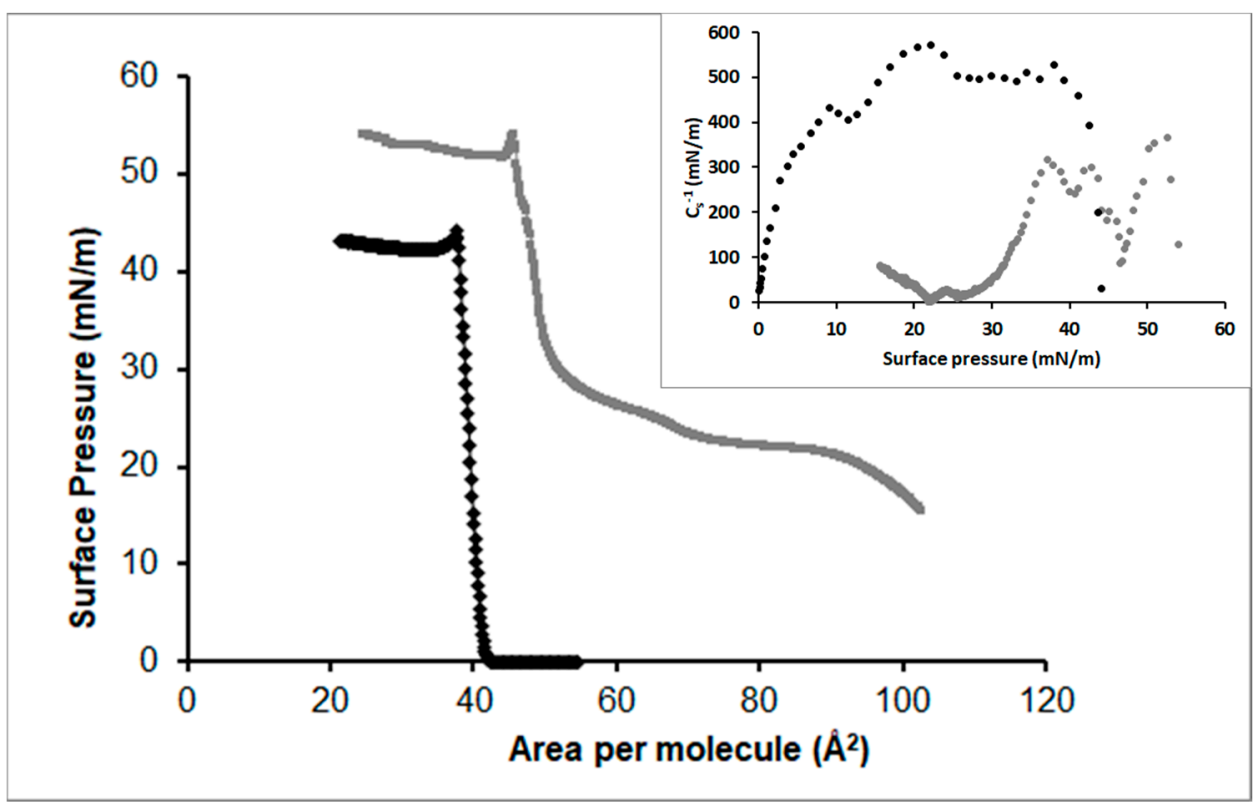

Figure 6. Surface pressure-area isotherms for $\mathrm{CHO}$ in the absence (black) and in the presence (grey) of lysozyme. Inset: Elastic modulus curves from the isotherms of Figure 6 for $\mathrm{CHO}$ in the absence (black) and in the presence (grey) of lysozyme.

\subsection{Influence of Lysozyme over Mixed Lipid Monolayers \\ 3.3.1. Oleic Acid-DPPC}

The isotherms of OA-DPPC mixtures (Figure 7) show a shape in between that of OA (Figure 3) and DPPC (Figure 4), being closer to that of DPPC as the content of it in the mixture increases. The surface pressure of the phase change of DPPC, from LE to LC state, changes with lipid composition and becomes higher in the mixtures, indicating that a certain degree of miscibility occurs between OA and DPPC. For instance, the phase change occurs at $7.5 \mathrm{mN} \cdot \mathrm{m}^{-1}$ for pure DPPC and at $11 \mathrm{mN} \cdot \mathrm{m}^{-1}$ for the OA-DPPC mixture with $\mathrm{X}_{\mathrm{OA}}=0.224$. These phase changes are clearly observed in the inset of Figure 7 with the 
elastic modulus plots. The values of $\Delta A$ (Equation (2)) are negative (see Table 1), which correspond to attractive or favorable interactions between the lipids.

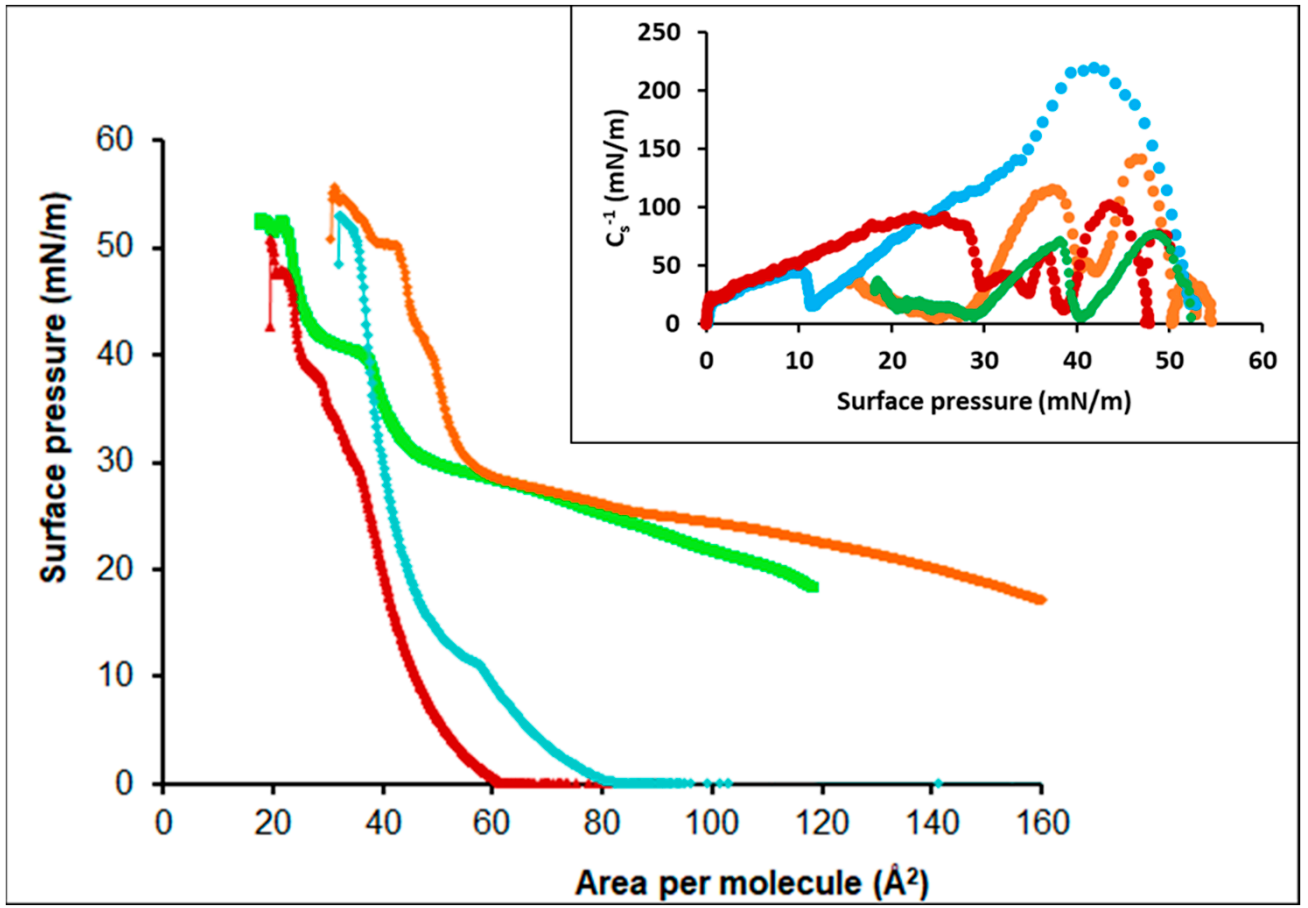

Figure 7. Surface pressure-area isotherms and elastic modulus curves (inset) for OA-DPPC mixtures: $\mathrm{X}_{\mathrm{OA}}=0.634$, in the absence (red) and in the presence (green) of lysozyme; $\mathrm{X}_{\mathrm{OA}}=0.224$, in the absence (blue) and in the presence (orange) of lysozyme.

Table 1. Excess area (in $\AA^{2} \cdot$ molecule ${ }^{-1}$ ) (see Equation (2)) for the mixed lípids at several surface pressures.

\begin{tabular}{ccccccc}
\hline $\begin{array}{c}\Pi \\
\left(\mathbf{m N} \cdot \mathbf{m}^{-1}\right)\end{array}$ & OA-DPPC $^{\mathbf{1}}$ & OA-DPPC $^{2}$ & OA-POPC $^{3}$ & OA-POPC $^{4}$ & CHO-POPC $^{\mathbf{5}}$ & CHO-POPC $^{6}$ \\
\hline 5 & -8.2 & -6.8 & -7.1 & -5.0 & -14.9 & -11.3 \\
\hline 15 & -0.9 & -0.7 & -5.1 & -3.3 & -10.1 & -8.2 \\
\hline 25 & -1.4 & -4.2 & -4.2 & -2.3 & -7.4 & -5.9 \\
\hline 35 & & & & & -5.7 & -4.4 \\
\hline
\end{tabular}

${ }^{1} \mathrm{X}_{\mathrm{OA}}=0.634,{ }^{2} \mathrm{X}_{\mathrm{OA}}=0.224,{ }^{3} \mathrm{X}_{\mathrm{OA}}=0.402,{ }^{4} \mathrm{X}_{\mathrm{OA}}=0.230,{ }^{5} \mathrm{X}_{\mathrm{CHO}}=0.567,{ }^{6} \mathrm{X}_{\mathrm{CHO}}=0.179$.

In the presence of lysozyme, it is observed, at first, that isotherms shift to higher area and surface pressure values, and that the effect of lysozyme is higher at lower surface pressures where a more fluid phase is present. These effects have also been observed in the other mixtures studied here. The isotherm of OA-DPPC at the higher OA content $\left(\mathrm{X}_{\mathrm{OA}}\right.$ $=0.634$ ) shows a shape more similar to that of OA in the presence of lysozyme (Figure 3 ) until a surface pressure of $40 \mathrm{mN} \cdot \mathrm{m}^{-1}$. Then, the isotherm presents an inflection related to a phase change, followed by a surface pressure increase until the collapse, with a behavior closer to that of DPPC. On the other hand, the isotherm of OA-DPPC at the lower OA content $\left(\mathrm{X}_{\mathrm{OA}}=0.224\right)$ shows a shape more similar to that of DPPC in the presence of lysozyme (Figure 4). At the surface pressure of $50 \mathrm{mN} \cdot \mathrm{m}^{-1}$, there is an inflection in the isotherm near the collapse, and thus the isotherm gets closer to that of the lipid mixture, indicating that lysozyme molecules are displaced from the surface at high surface pressures. This is due to the higher degree of compactness of DPPC, the major component in this mixture. The effect of lysozyme on the collapse surface pressure is slight ( 49 and $50 \mathrm{mN} \cdot \mathrm{m}^{-1}$ 
for the mixture with $\mathrm{X}_{\mathrm{OA}}=0.634$ and without and with lysozyme, respectively; and 51 and $53 \mathrm{mN} \cdot \mathrm{m}^{-1}$ for the mixture with $\mathrm{X}_{\mathrm{OA}}=0.224$ and without and with lysozyme, respectively).

Analyzing the values of $C_{S}{ }^{-1}$ (inset of Figure 7), it is seen that in the absence of lysozyme, a LC state is reached for the mixture with higher DPPC content. Meanwhile, the mixture with lower DPPC content presents several inflections, and the maximum value of $C_{S}{ }^{-1}$ hardly arrives at $100 \mathrm{mN} \cdot \mathrm{m}^{-1}$, indicating a higher degree of fluidity of this mixture due to the higher content of OA, which is less rigid than DPPC. In the presence of lysozyme, several inflections are clearly seen, and the values of $C_{S}{ }^{-1}$ always remain in the LE state for the mixture with higher OA content. However, the values of $C_{S}{ }^{-1}$ arrive at the LC state for the mixture with the higher DPPC content, even though the values of $C_{S}{ }^{-1}$ are always lower than those of the mixture in the absence of lysozyme.

\subsubsection{Oleic Acid-POPC}

The isotherms of OA-POPC mixtures (Figure 8) show a shape in between that of OA (Figure 3) and POPC (Figure 5). These isotherms only show a weak inflection at high surface pressures, probably due to a certain phase separation between OA and POPC. The surface pressure at which the inflection occurs depends on composition, taking place at a lower surface pressure when the OA content is higher. The values of $\Delta A$ (Equation (2)) are negative (see Table 1), which correspond to attractive or favorable interactions between the lipids.

In the presence of lysozyme, the shape of the isotherms is similar in both mixtures, presenting practically the same collapse surface pressure $\left(47 \mathrm{mN} \cdot \mathrm{m}^{-1}\right.$ for the mixture with $\mathrm{X}_{\mathrm{OA}}=0.402$ and $47 \mathrm{mN} \cdot \mathrm{m}^{-1}$ for the mixture with $\left.\mathrm{X}_{\mathrm{OA}}=0.230\right)$. The shape is also close to that of the mixed lipids in the absence of lysozyme $\left(48 \mathrm{~N} \cdot \mathrm{m}^{-1}\right.$ for the mixture with $\mathrm{X}_{\mathrm{OA}}=0.402$ and $50 \mathrm{mN} \cdot \mathrm{m}^{-1}$ for the mixture with $\left.\mathrm{X}_{\mathrm{OA}}=0.230\right)$. The isotherms in the presence of lysozyme are shifted to higher areas in respect to those in the absence of lysozyme.

Analyzing the values of $C_{S}^{-1}$ (inset Figure 8), it is seen that in the absence of lysozyme, these values indicate a LE state, even closer to a LC state for the mixture with the higher POPC content and at high compression. In the presence of lysozyme, the values of $C_{S}{ }^{-1}$ are lower at low surface pressures but reach values similar to those in the absence of lysozyme at high surface pressures. This fact indicates that even some lysozyme molecules remain on the surface at high surface pressures, since the isotherms are shifted to higher areas, the fluidity of the monolayer is similar to that in its absence.

\subsubsection{Cholesterol-POPC}

The isotherms of CHO-POPC mixtures (Figure 9) show a shape in between that of $\mathrm{CHO}$ (Figure 6) and POPC (Figure 5), being closer to that of $\mathrm{CHO}$ as the content of it in the mixture increases. The values of $\Delta A$ (Equation (2)) are negative (see Table 1), which correspond to attractive or favorable interactions between the lipids. It is also seen that these values are the most negative of the studied mixed lipids. A weak inflection is observed at high surface pressures, slightly higher than that of $\mathrm{CHO}$ collapse, which indicates a partial phase separation between $\mathrm{CHO}$ and POPC at these high values of the surface pressure.

In the presence of lysozyme, the shape of the isotherms is relatively similar in both mixtures, presenting practically the same collapse surface pressure $\left(50 \mathrm{mN} \cdot \mathrm{m}^{-1}\right.$ for the mixture with $\mathrm{X}_{\mathrm{CHO}}=0.567$ and $48 \mathrm{mN} \cdot \mathrm{m}^{-1}$ for the mixture with $\mathrm{X}_{\mathrm{CHO}}=0.179$ ). The shape is also close to that of the mixed lipids in the absence of lysozyme $\left(49 \mathrm{mN} \cdot \mathrm{m}^{-1}\right.$ for the mixture with $\mathrm{X}_{\mathrm{CHO}}=0.567$ and $49 \mathrm{mN} \cdot \mathrm{m}^{-1}$ for the mixture with $\left.\mathrm{X}_{\mathrm{CHO}}=0.179\right)$. The isotherms in the presence of lysozyme are shifted to higher areas in respect to those in the absence of lysozyme. 


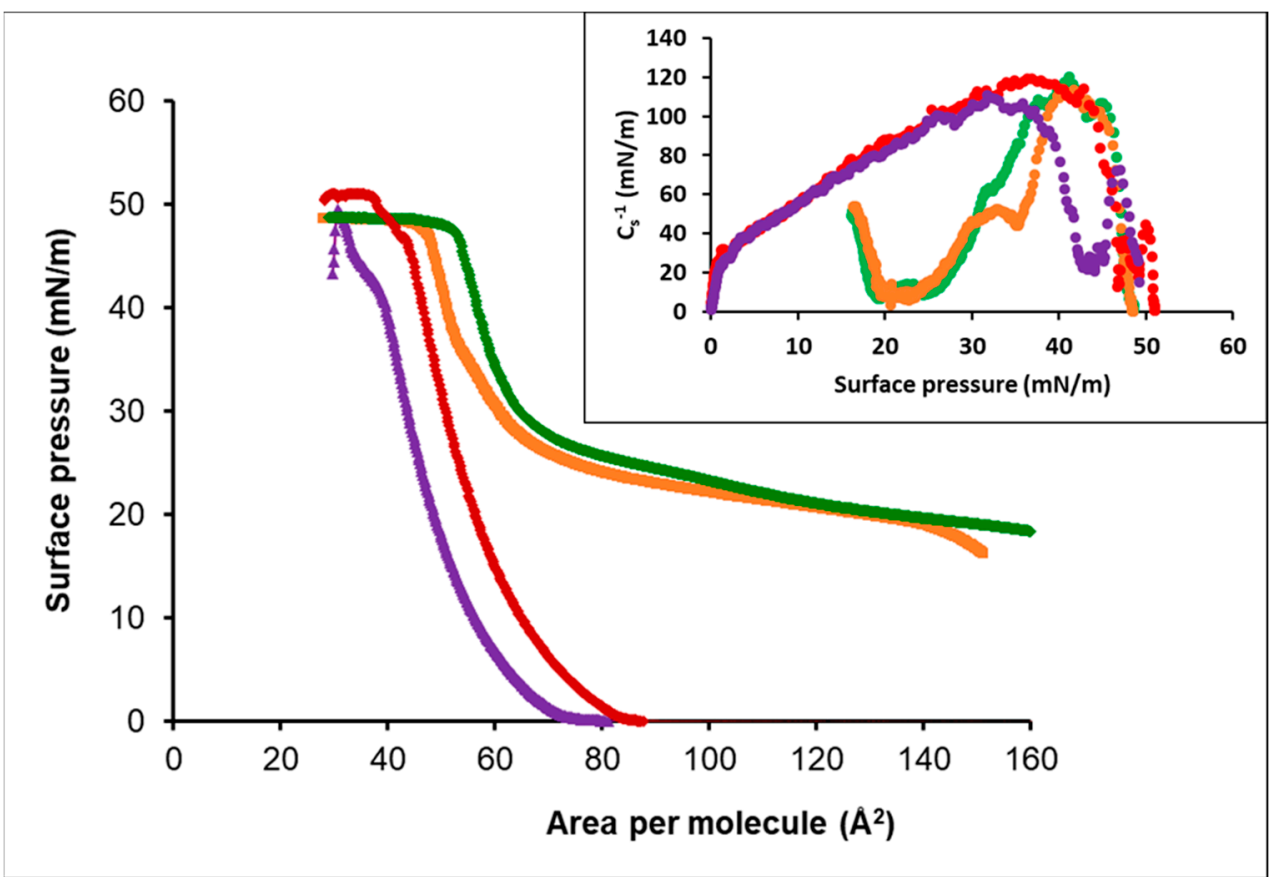

Figure 8. Surface pressure-area isotherms and elastic modulus curves (inset) for OA-POPC mixtures: $\mathrm{X}_{\mathrm{OA}}=0.402$, in the absence (violet) and in the presence (orange) of lysozyme; $\mathrm{X}_{\mathrm{OA}}=0.230$, in the absence (red) and in the presence (green) of lysozyme.

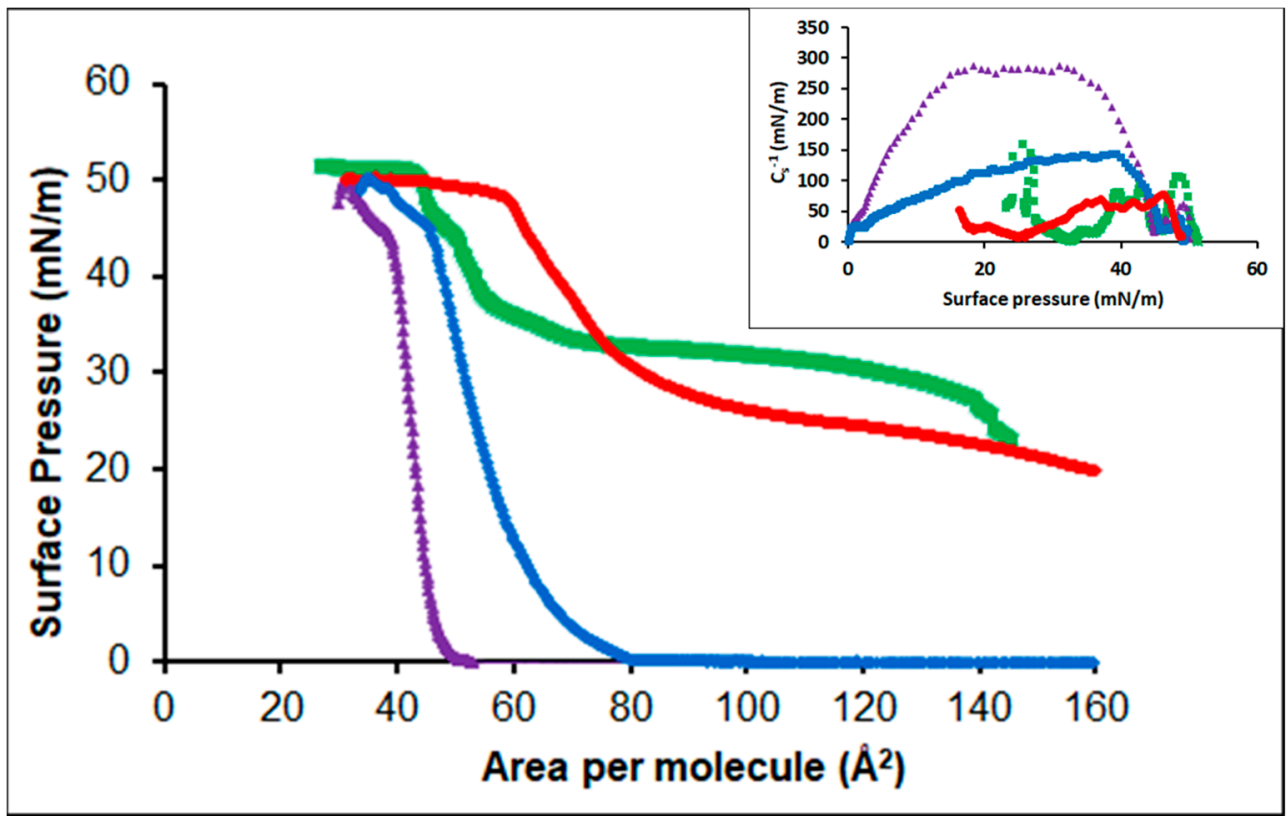

Figure 9. Surface pressure-area isotherms and elastic modulus curves (inset) for CHO-POPC mixtures: $\mathrm{X}_{\mathrm{CHO}}=0.567$, in the absence (violet) and in the presence (green) of lysozyme; $\mathrm{X}_{\mathrm{CHO}}=0.179$, in the absence (blue) and in the presence (red) of lysozyme.

Analyzing the values of $C_{S}{ }^{-1}$ (inset Figure 9), it is seen that in the absence of lysozyme, these values indicate a LC state, especially for the mixture with high $\mathrm{CHO}$ content. This is due to the high rigidity of CHO. In the presence of lysozyme, a LE state is always observed, only reaching values close to a LC state at high compression. 


\section{Discussion}

\subsection{Individual Lipids}

Different behaviors have been observed in the influence of lysozyme on lipid monolayers spread over a saline subphase, depending on the lipid, but the isotherm shape in the presence of lysozyme is very similar at low compressions for all lipids. This could indicate that at the first stages of compression, the monolayer behavior is more dependent on the protein. Advention flow (convection towards the interface) occurs due to solvent evaporation [38]. In the case of lipids spread on an aqueous subphase, which form a surface layer, and using a closed chamber as in the present work, it can be assumed that solvent evaporation is weak or null. Thus, no protein multilayer formation should occur [38], but this point would need future research using surface physical techniques.

Concerning the fatty acids and cholesterol, when compressing the SA, which forms compact monolayers, lysozyme is practically expelled at high surface pressures (the difference in area between isotherms in the absence and in the presence of lysozyme is very small, as well as the difference in the collapse). This expulsion is gradual with the change of state of the SA monolayer. For OA, which does not form monolayers as compact as SA does, the expulsion of lysozyme is not so important (the difference in area between isotherms in the absence and in the presence of lysozyme is significant even at high surface pressures, and the collapse surface pressure increases). For cholesterol, even though it forms compact monolayers, the presence of lysozyme at the surface is notable (the difference in area between isotherms in the absence and in the presence of lysozyme is significant even at high surface pressures, and the collapse surface pressure increases), showing a behavior more similar to OA than to SA. This could be due to the lower hydrophilic character of cholesterol in respect to SA and a higher hydrophobic interaction between hydrocarbon chains of cholesterol and lysozyme.

Concerning the phospholipids, for DPPC, the expulsion of lysozyme is practically total at high surface pressures and near the collapse (the difference in area between isotherms in the absence and in the presence of lysozyme is practically null, and the collapse surface pressure is only slightly different). For POPC, there is also an expulsion practically total at surface pressures near the collapse (the difference in area between isotherms in the absence and in the presence of lysozyme is practically null, and the collapse surface pressure is practically the same). In contrast with DPPC, POPC shows positive values of $\Delta A$ at high surface pressures below the collapse. This could be explained by the fact that POPC forms monolayers less compact than DPPC due to the unsaturation present in one of the hydrocarbon chains.

DPPC and POPC are zwitterion phospholipids, and at a surface pressure around $33 \mathrm{mN} \cdot \mathrm{m}^{-1}$, close to the physiological lateral pressure value of natural membranes (in between 30 and $35 \mathrm{mN} \cdot \mathrm{m}^{-1}$ [47]), the fluidity effect of lysozyme on the phospholipid monolayer is still seen. Gorbenko et al. [37] studied the binding of lysozyme to phospholipid bilayers and found an influence of the content of anionic phospholipids on the binding of lysozyme, and also found that lysozyme increases acyl-chain order for liposomes in the presence of anionic phospholipids. In our case, as DPPC and POPC are zwitterion phospholipids, cholesterol is neutral, and SA and $\mathrm{OA}\left(\mathrm{pK}_{\mathrm{a}}(\mathrm{SA})=5.63\right.$ and $\mathrm{pK}_{\mathrm{a}}(\mathrm{OA})=6.22$ [48] show a weak negative charge at the $\mathrm{pH}=5.0$ of the subphase, the electrostatic interactions seem to have a weak or no effect. Nevertheless, comparing the results of the present work, in $0.9 \% \mathrm{NaCl}$ subphase, with those of previous work [39] in water subphase, a notable influence of the subphase is observed. The influence of lysozyme becomes more important when $0.9 \% \mathrm{NaCl}$ is present in the subphase, as this saline solution is closest to physiological media. A possible explanation for this fact could be attributed to the effect of sodium ions. Sodium ions could bind or adsorb on the negative or hydroxylated groups of the monolayer (phosphate, carboxylate, $\mathrm{OH}$ ), increasing the electrostatic repulsion with lysozyme, which is positively charged (IEP $=11.4$ ).

Comparing all the lipids at high surface pressures, in the presence of lysozyme, SA and DPPC show similar behavior due to the absence of unsaturation in the hydrocarbon 
chains. On the other hand, OA and POPC show differences in spite of the presence of unsaturation, which could be explained by the fact that POPC also has a saturated chain that allows it to form monolayers that are more compact than those of OA. Cholesterol presents a specific behavior since, despite forming compact monolayers, its behavior is more similar to that of OA than to the other lipids.

Compressibility curves show a clear descent of the values of $C_{S}{ }^{-1}$ in the presence of lysozyme at low and intermediate surface pressures, with values closer to those of pure lipids at high surface pressures but without reaching them. This behavior can be explained by the fact that lysozyme molecules are present on the surface and inhibit the packing of the lipid monolayer or make it more difficult. The interaction of lysozyme at a surface pressure around $33 \mathrm{mN} \cdot \mathrm{m}^{-1}$, close to the physiological value of natural membranes, is more important with cholesterol and OA, or even with SA, than with the phospholipids DPPC and POPC. Particularly, cholesterol in the presence of lysozyme also shows high values of the elastic modulus even though isotherms indicate the presence of lysozyme in the monolayer.

The multiple inflections observed in the isotherms in the presence of lysozyme correspond to the reorientation or reorganization of the lysozyme molecules or of the lipid molecules in the presence of lysozyme. In the case of the fatty acids, SA and OA, as well as for cholesterol, one of these inflections corresponds with the collapse surface pressure of the pure lipid, which does not hold for the phospholipids POPC and DPPC. This is in agreement with the behaviors delineated previously.

Derde et al. [35,36] found that lysozyme is able to insert itself into a bacterial phospholipid monolayer, resulting in lipid packing reorganization. They stated that a protein could modify the lipid packing simply by adsorbing onto the lipid headgroups and that protein insertion is not a prerequisite for monolayer packing modifications. A notable effect of lysozyme was also observed on the surface pressure-area isotherm of an artificial lipid tear [41], whose main components are phosphatidylcholine phospholipids. Very low values of $C_{S}{ }^{-1}$ were obtained, indicating a notable fluidization effect of lysozyme over the monolayer of the lipid artificial tear.

\subsection{Mixed Lipids}

In mixed lipid monolayers, the influence of lysozyme on the surface pressure-area isotherms is important at low surfaces pressures and similar for all the mixtures. At intermediate and high surface pressures, the influence of lysozyme depends on the mixed lipids and their content, but as at least one of the studied lipid components shows a significant influence of lysozyme in the individual monolayer, this also occurs in the mixture. Only the mixtures with DPPC show less influence at high surface pressures, according to the behavior shown by individual DPPC.

It is worth commenting on the different behavior of the DPPC mixtures in respect to those of CHO. DPPC and CHO form compact monolayers, but in the presence of lysozyme, the $\mathrm{CHO}$ isotherm shows a stronger shift to higher areas at high surface pressures. This behavior is also present in the studied mixtures, which reinforces the idea discussed in the previous section that $\mathrm{CHO}$ has specific behavior.

Looking at the monolayer compressibility through the elastic modulus plots $C_{S}{ }^{-1}$ it is seen that at low and moderate surface pressures, all the mixtures in the presence of lysozyme show lower values of $C_{S}{ }^{-1}$; that is, monolayers are in a more fluid state. However, at high surface pressures, practically all the mixtures present a maximum value of $C_{S}{ }^{-1}$ near $100 \mathrm{mN} \cdot \mathrm{m}^{-1}$, even though it depends on the lipid composition and content. Again a specific behavior is observed for $\mathrm{CHO}$ mixtures, where lower values of $C_{S}{ }^{-1}$ than expected occurs due to the $\mathrm{CHO}$ presence, not reaching a value of $100 \mathrm{mN} \cdot \mathrm{m}^{-1}$ (when the maximum $\mathrm{C}_{S}{ }^{-1}$ value is around $280 \mathrm{mN} \cdot \mathrm{m}^{-1}$ for the mixture with higher $\mathrm{CHO}$ content and around $500 \mathrm{mN} \cdot \mathrm{m}^{-1}$ for the individual $\mathrm{CHO}$ ). 


\section{Conclusions}

According to surface pressure-area isotherms and compressibility plots, it is observed that lysozyme affects lipid monolayer formation. This influence is more important at low and moderate surface pressures, but at high surface pressures and near the physiological value of lateral pressure of $33 \mathrm{mN} \cdot \mathrm{m}^{-1}$, there is an expulsion of lysozyme out of the monolayer. This expulsion is more important for SA, DPPC, and POPC, while for OA and cholesterol, the isotherms indicate that a residual content of lysozyme remains in the monolayer. In the case of the studied lipid mixtures (OA-DPPC, OA-POPC, CHO-POPC), there is always some lysozyme remaining in the monolayer, but the expulsion is more important when DPPC is present. As the elastic modulus values decrease in the presence of lysozyme, this indicates that lysozyme makes the monolayer more fluid, especially up to moderate surface pressures, and generally in the LE state. In the presence of lysozyme, cholesterol presents the highest value of elastic modulus and corresponds to a LC state at high compressions. This result is interesting since cholesterol isotherms indicate that some lysozyme remains in the monolayer, which could suggest that lysozyme molecules arrange well in the monolayer with cholesterol forming a compact layer, a fact that could be related to the role of cholesterol in biological membranes. The results obtained in the present work could also be of interest in the design of new lipid artificial tears. An open question that remains is to better study the phase separation in the studied mixed lipids and the possible differential interaction of lysozyme with the formed phases.

Supplementary Materials: The following supporting information can be downloaded at: https: //www.mdpi.com/article/10.3390/colloids6010015/s1. Table S1: Values of $\mathrm{Cs}^{-1}$ for different film states.

Funding: This research received no external funding.

Conflicts of Interest: The author declares no conflict of interest.

\section{References}

1. Ulman, A. An Introduction to Ultrathin Organic Films; Academic Press: Boston, MA, USA, 1990.

2. Petty, M.C. Langmuir-Blodgett Films: An Introduction; Cambridge University Press: Cambridge, MA, USA, 1996.

3. Richardson, T.H. (Ed.) Functional Organic and Polymeric Materials: Molecular Functionality-Macroscopic Reality; Wiley: Chichester, UK, 2000.

4. Torrent-Burgués, J. Thermodynamic behaviour of mixed films of an unsaturated and a saturated polar lipid. (Oleic acid-stearic acid and POPC-DPPC). Colloids Interfaces 2018, 2, 17. [CrossRef]

5. Eftaiha, A.F.; Brunet, S.M.K.; Paige, M.F. Thermodynamic and structural characterization of a mixed perfluorocarbonphospholipid ternary monolayer surfactant system. J. Colloid Interface Sci. 2012, 368, 356-365. [CrossRef] [PubMed]

6. Gzyl-Malcher, B.; Paluch, M. Studies of lipid interactions in mixed Langmuir monolayers. Thin Solid Films 2008, 516, 8865-8872. [CrossRef]

7. Hac-Wydro, K.; Wydro, P. The influence of fatty acids on model cholesterol-phospholipd membranes. Chem. Phys. Lipids 2007, 150, 66-81. [CrossRef] [PubMed]

8. Hac-Wydro, K.; Jedrzejek, K.; Dynarowicz-Łatka, P. Effect of saturation degree on the interactions between fatty acids and phosphatidylcholines in binary and ternary Langmuir monolayers. Colloids Surf. B Biointerfaces 2009, 72, 101-111. [CrossRef] [PubMed]

9. He, G.; Sun, R.; Hao, C.; Yang, J.; Wang, M.; Zhang, L. Thermodynamic analysis and AFM study of the interaction of palmitic acid with DPPE in Langmuir monolayers. Colloids Surf. A Physicochem. Eng. Asp. 2014, 441, 184-194. [CrossRef]

10. Hao, C.; Sun, R.; Zhang, J. Mixed onolayers of DOPC and palmitic acid at the liquid-air interface. Colloids Surf. B Biointerfaces 2013, 112, 441-445. [CrossRef]

11. Hoda, K.; Nakahara, H.; Nakamura, S.; Nagadome, S.; Sugihara, G.; Yoshino, N.; Shibata, O. Langmuir monolayer properties of the fluorinated-hydrogenated hybrid amphiphiles with dipalmitoylphosphatidylcholine (DPPC). Colloids Surf. B Biointerfaces 2006, 47, 165-175. [CrossRef]

12. Hoda, K.; Kawasaki, H.; Yoshino, N.; Chang, C.-H.; Morikawa, Y.; Sugihara, G.; Shibata, O. Mode of interaction of two fluorinatedhydrogenated hybrid amphiphiles with dipalmitoylphosphatidylcholine (DPPC) at the air-water interface. Colloids Surf. B Biointerfaces 2006, 53, 37-50. [CrossRef]

13. Nakahara, H.; Nakamura, S.; Kawasaki, H.; Shibata, O. Properties of two-component Langmuir monolayer of single chain perfluorinated carboxylic acids with dipalmitoylphosphatidylcholine (DPPC). Colloids Surf. B Biointerfaces 2005, 41, 285-298. [CrossRef] 
14. Petelska, A.D.; Figaszewski, Z.A. The equilibria of phosphatidylcholine-fatty acid and phosphatidylcholine-amine in monolayers at the air/water interface. Colloids Surf. B Biointerfaces 2011, 82, 340-344. [CrossRef]

15. Torrent-Burgués, J. Oleamide and oleamide-lipid mixed monolayers. Bionanoscience 2011, 1, 202-209. [CrossRef]

16. Miñones, J., Jr.; Pais, S.; Miñones, J.; Conde, O.; Dynarowicz-Łątka, P. Interactions between membrane sterols and phospholipids in model mammalian and fungi cellular membranes-A Langmuir monolayer study. Biophys. Chem. 2009, 140, 66-77. [CrossRef] [PubMed]

17. Chou, T.-H.; Chang, C.-H. Thermodynamic behavior and relaxation processes of mixed DPPC/cholesterol monolayers at the air/water interface. Colloids Surf. B 2000, 17, 71-79. [CrossRef]

18. Drolle, E.; Kucerka, N.; Hoopes, M.I.; Choi, Y.; Katsaras, J.; Karttunen, M.; Leonenko, Z. Effect of melatonin and cholesterol on the structure of DOPC and DPPC membranes. Biochim. Biophys. Acta 2013, 1828, 2247-2254. [CrossRef]

19. Dynarowicz-Łatka, P.; Haç-Wydro, K. Interactions between phosphatidylcholines and colesterol in monolayers at the air/water interface. Colloids Surf. B 2004, 37, 21-25. [CrossRef]

20. Haç-Wydro, K.; Wydro, P.; Dynarowicz-Łatka, P.; Paluch, M. Cholesterol and phytosterols effect on sphingomyelin/phosphatidylcholine model Membranes-Thermodynamic analysis of the interactions in ternary monolayers. J. Colloid Interface Sci. 2009, 329, $265-272$. [CrossRef]

21. Korchowiec, B.; Paluch, M.; Corvis, Y.; Rogalska, E. A Langmuir film approach to elucidating interactions in lipid membranes: 1,2-dipalmitoyl-sn-glycero-3-phosphoethanolamine/cholesterol/metal cation Systems. Chem. Phys. Lipids 2006, 144, 127-136. [CrossRef]

22. Wydro, P. The influence of cholesterol on multicomponent Langmuir monolayers imitating outer and inner leaflet of human erythrocyte membrane. Colloids Surf. B 2013, 103, 67-74. [CrossRef]

23. Ulaganathan, V.; Retzlaff, I.; Won, J.Y.; Gunes, D.Z.; Gochev, G.; Gehin-Delval, C.; Leser, M.; Noskov, B.A.; Miller, R. $\beta$ Lactoglobulin adsorption layers at the water/air surface: 2. Dilational rheology: Effect of $\mathrm{pH}$ and ionic strength. Colloids Surf. A 2017, 521, 167-176. [CrossRef]

24. Mahmoudi, N.; Gaillard, C.; Boué, F.; Axelos, M.A.V.; Riaublanc, A. Self-similar assemblies of globular whey proteins at the air-water interface: Effect of the structure. J. Colloid Interface Sci. 2010, 345, 54-63. [CrossRef] [PubMed]

25. Miñones-Conde, M.; Conde, O.; Trillo, J.M.; Miñones, J., Jr. How to obtain a well-spread monolayer of lysozyme at the air-water interfaces. J. Colloid Interface Sci. 2011, 361, 351-360. [CrossRef] [PubMed]

26. Sah, B.K.; Kundu, S. Modification of hysteresis behaviors of protein monolayer and the corresponding structures with the variation of the protein surface charges. Colloids Surf. B 2017, 159, 696-704. [CrossRef]

27. Tihonov, M.M.; Milyaeva, O.Y.; Noskov, B.A. Dynamic surface properties of lysozyme solutions. Impact of urea and guanidine hydrochloride. Colloids Surf. B 2015, 129, 114-120. [CrossRef] [PubMed]

28. Chernysheva, M.G.; Badun, G.A.; Shnitko, A.V.; Petrova, V.I.; Ksenofontov, A.L. Lysozyme-surfactant adsorption at the aqueousair and aqueous-organic liquid interfaces as studied by tritium probe. Colloids Surf. A 2018, 537, 351-360. [CrossRef]

29. Girard-Egrot, A.P.; Godoy, S.; Blum, L.J. Enzyme association with lipidic Langmuir-Blodgett films: Interests and applications in nanobioscience. Adv. Colloid Interface Sci. 2005, 116, 205-225. [CrossRef] [PubMed]

30. Kamylya, T.; Pal, P.; Talapatra, G.B. Incorporation of ovalbumin within cationic octadecylamine monolayer and a comparative study with zwitterionic DPPC and anionic stearic acid monolayer. J. Colloid Interface Sci. 2007, 315, 464-474. [CrossRef]

31. Lai, L.; Wei, X.-Q.; Huang, W.-H.; Mei, P.; Ren, Z.-H.; Liu, Y. Impact of carbon quantum dots on dynamic properties of BSA and BSA/DPPC adsorption layers. J. Colloid Interface Sci. 2017, 506, 245-254. [CrossRef]

32. Nishimura, S.Y.; Magana, G.M.; Ketelson, H.A.; Fuller, G.G. Effect of Lysozyme Adsorption on the Interfacial Rheology of DPPC and Cholesteryl Myristate Films. Langmuir 2008, 24, 11728-11733. [CrossRef]

33. Ohno, M.; Toyota, T.; Nomoto, T.; Fujinami, M. Interfacial tension in adsorption of lysozyme onto a lipid monolayer formed at a water/choloform interface. Colloids Surf. A 2015, 480, 85-90. [CrossRef]

34. Vázquez, R.F.; Daza Millone, M.A.; Pavinatto, F.J.; Herlax, V.S.; Bakás, L.S.; Oliveira, O.N., Jr.; Vela, M.E.; Maté, S.M. Interaction of acylated and unacylated forms of E. coli alpha-hemolysin with lipid monolayers: A PM-IRRAS study. Colloids Surf. B 2017, 158, 76-83. [CrossRef] [PubMed]

35. Derde, M.; Nau, F.; Lechevalier, V.; Guérin-Dubiard, C.; Paboeuf, G.; Jan, S.; Baron, F.; Gautier, M.; Vié, V. Native lysozyme and dry-heated lysozyme interactions with membrane lipid monolayers: Lateral reorganization of LPS monolayer, model of the Escherichia coli outer membrane. Biochim. Biophys. Acta 2015, 1848, 174-183. [CrossRef] [PubMed]

36. Derde, M.; Nau, F.; Guérin-Dubiard, C.; Lechevalier, V.; Paboeuf, G.; Jan, S.; Baron, F.; Gautier, M.; Vié, V. Native and dry-heated lysozyme interactions with membrane lípid monolayers: Lipid packing modifications of a phospholipid mixture, model of the Escherichia coli cytoplasmic membrane. Biochim. Biophys. Acta 2015, 1848, 1065-1073. [CrossRef] [PubMed]

37. Gorbenko, G.P.; Ioffe, V.M.; Kinnunen, P.K.J. Binding of Lysozyme to Phospholipid Bilayers: Evidence for Protein Aggregation upon Membrane Association. Biophys. J. 2007, 93, 140-153. [CrossRef] [PubMed]

38. Pasquier, C.; Pezennec, S.; Bouchoux, A.; Cabane, B.; Lechevalier, V.; Le Floch-Fouéré, C.; Paboeuf, G.; Pasco, M.; Dollet, B.; Lee, L.-T.; et al. Protein Transport upon Advection at the Air/Water Interface: When Charge Matters. Langmuir 2021, 37, 12278-12289. [CrossRef]

39. Torrent-Burgués, J.; Raju, R. Effect of lysozyme subphase and insertion on several lipid films. Adv. Mater. Sci. 2019, 4, 1-7. 
40. Nobre, T.M.; Pavinatto, F.J.; Caselli, L.; Barros-Timmons, A.; Dynarowicz-Latka, P.; Oliveira, O.N., Jr. Interactions of bioactive molecules \& nanomaterials with Langmuir monolayers as cell membrane models. Thin Solid Films 2015, 593, 158-188.

41. Torrent-Burgués, J.; Hoyo, J.; Tzanov, T. Lipid artificial tears at a mimetic ocular interface. Chem. Phys. Lipids 2021, 238, 105087. [CrossRef]

42. Crawford, N.F.; Micic, M.; Orbulescu, J.; Weissbart, D.; Leblanc, R.M. Surface chemistry and spectroscopy of the $\beta$-galactosidase Langmuir monolayer. J. Colloid Interface Sci. 2015, 453, 202-208. [CrossRef]

43. Krajewska, B.; Wydro, P.; Janczyk, A. Probing the Modes of Antibacterial Activity of Chitosan. Effects of pH and Molecular Weight on Chitosan Interactions with Membrane Lipids in Langmuir Films. Biomacromolecules 2011, 12, 4144-4152. [CrossRef]

44. Vitovič, P.; Nikolelis, D.P.; Hianik, T. Study of calix [4] resorcinarene-dopamine com-plexation in mixed phospholipid monolayers formed at the air I water interface. Biochim. Biophys. Acta 2006, 1758, 1852-1861. [CrossRef] [PubMed]

45. Davies, J.T.; Rideal, E.K. Interfacial Phenomena; Academic Press: Cambridge, MA, USA, 1993.

46. Caseli, L.; Crespilho, F.N.; Nobre, T.M.; Zaniquelli, M.D.; Zucolotto, V.; Oliveira, O.N., Jr. Using phospholipid Langmuir and Langmuir-Blodgett films as matrix for urease immobilization. J. Colloid Interface Sci. 2008, 319, 100-108. [CrossRef] [PubMed]

47. Marsh, D. Lateral pressure in membranes. Biochim. Biophys. Acta 1996, 1286, 183-223. [CrossRef]

48. Tomoaia-Cotisol, M.; Zsako, J.; Mocanu, A.; Lupea, M.; Chifu, E. Insoluble mixed monolayers: III. The ionization characteristics of some fatty acids at the air/water interface. J. Colloid Interface Sci. 1987, 117, 464-476. [CrossRef] 